
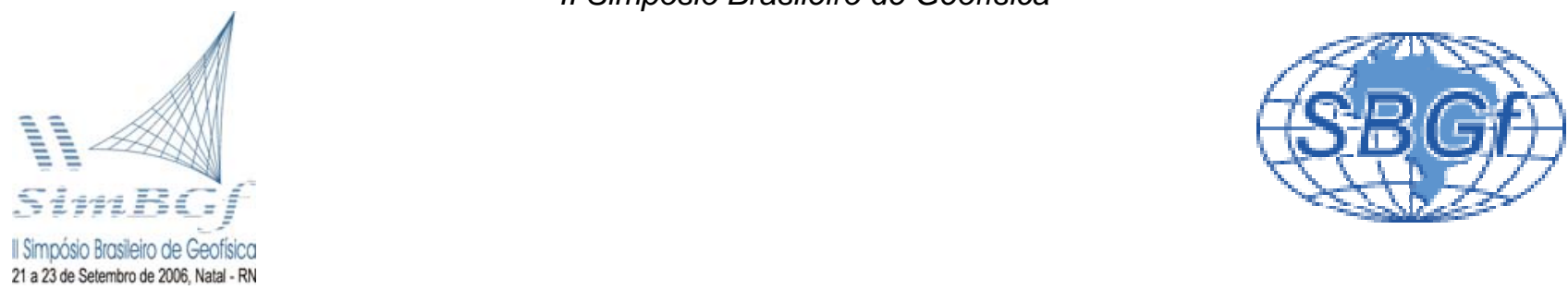

\title{
Aplicação de levantamentos aerogeofísicos magnético e eletromagnético e da eletro- resistividade na pesquisa hidrogeológica em terrenos cristalinos: 0 caso de Serrinha/RN, Nordeste do Brasil.
}

Carlos César Nascimento da Silva, Petrobras/UN-RNCE/ATEX/PS*

Walter Eugênio de Medeiros, UFRN/CCET/DFTE

Emanuel Ferraz Jardim de Sá, UFRN/CCET/PPGG

Maria da Guia Lima, UFRN/CCET/PPGG

Copyright 2006, SBGf - Sociedade Brasileira de Geofísica

Este texto foi preparado para a apresentação no II Simpósio de Geofísica da Sociedade Brasileira de Geofísica, Natal-RN, 21-23 de setembro de 2006. Seu conteúdo foi revisado pela Comissão Tecno-científica do II SR-SBGf mas não necessariamente representa a opinĩ̃o da SBGf ou de seus associados. É proibida a reprodução total ou parcial deste material para propósitos comerciais sem prévia autorização da SBGf.

\section{Resumo}

Aproximadamente $50 \%$ do substrato do NE brasileiro é composto por rochas cristalinas, inseridas em ambiente de clima semi-árido. Neste contexto, o êxito em encontrar água em subsuperfície é proporcional à capacidade de existirem, e identificar, descontinuidades nas rochas capazes de servirem como meio aqüífero. Métodos geofísicos aeroportados têm a capacidade de imagear amplas áreas e, com o detalhe dos métodos terrestres, delimitar as zonas hidrogeologicamente importantes. A complexidade do embasamento cristalino pode então ser desvendada a partir da correlação entre a geofísica, a geologia estrutural enfocando a neotectônica e os modelos disponíveis de fluxo e armazenamento de água subterrânea em terrenos cristalinos.

\section{Introdução}

Na Região Nordeste do Brasil o clima dominante semiárido desfavorece a retenção da água durante longos períodos em reservatórios superficiais. Adicionalmente, cerca de $50 \%$ do substrato do NE brasileiro é composto por rochas cristalinas com capacidade de armazenamento de água somente em descontinuidades (fraturas, foliação, etc). No trabalho de locação de poços no cristalino, discernir as estruturas com maior potencial hidrogeológico é difícil e rotineiramente faz uso apenas da interpretação de aerofotos convencionais seguida da análise geológica-estrutural de campo. O modelo de fluxo e armazenamento normalmente usado é chamado riacho-fenda (Siqueira 1963) que associa trechos retilíneos de drenagens a zonas de fraturas subverticalizadas. Esporadicamente, empregam-se métodos geofísicos elétricos ou eletromagnéticos terrestres. Nas condições usuais, a locação ainda envolve índices de acerto relativamente baixos, em torno de $70 \%$, considerando como poço produtivo aquele cuja vazão é superior a $500 \mathrm{l} / \mathrm{h}$.

Em conseqüência desta abordagem utilizada na locação, há diversas questões: (i) existem zonas de fraturas hidrogeologicamente importantes não relacionadas às drenagens? (ii) como é o comportamento 3D das descontinuidades capazes de armazenar água? (iii) os modelos de fluxo e armazenamento de água subterrânea no cristalino descritos na literatura são adequados (Jardim de Sá et al., 2003)? (iv) em particular, o modelo calha elúvio-aluvionar (Silva 2000), associado à formação de calhas de sedimento e/ou regolito aproveitando espaços intemperizados da foliação poderá ter elevada importância hidrogeológica ou ele representa somente uma "armadilha" para o intérprete durante a locação, podendo explicar boa parte de seu insucesso?

Para responder estas questões, dentre outras, foi firmado entre instituições brasileiras e canadenses, um convênio multidisciplinar denominado Projeto Água Subterrânea no Nordeste do Brasil (PROASNE). Dentre as ferramentas disponibilizadas pelo PROASNE, foi executado de forma inédita para as condições geológicas, climáticas e de objetivos, um levantamento aerogeofísico que incluiu medidas do campo magnético natural e do campo eletromagnético artificial no domínio da freqüência. Foram realizados três levantamentos aerogeofísicos nas áreas-piloto de Serrinha/RN, Samambaia/PE e Juá/CE. Neste trabalho, serão discutidas as informações referentes à área de Serrinha/RN (Fig. 01), integradas com dados complementares de geologia e de geofísica terrestre. O objetivo principal é discutir os modelos de ocorrência da água subterrânea no cristalino, contribuindo às respostas das questões anteriormente formuladas e pretender dar subsídios ao aumento no índice de acerto nas locações, mesmo utilizando as ferramentas tradicionais de locação.

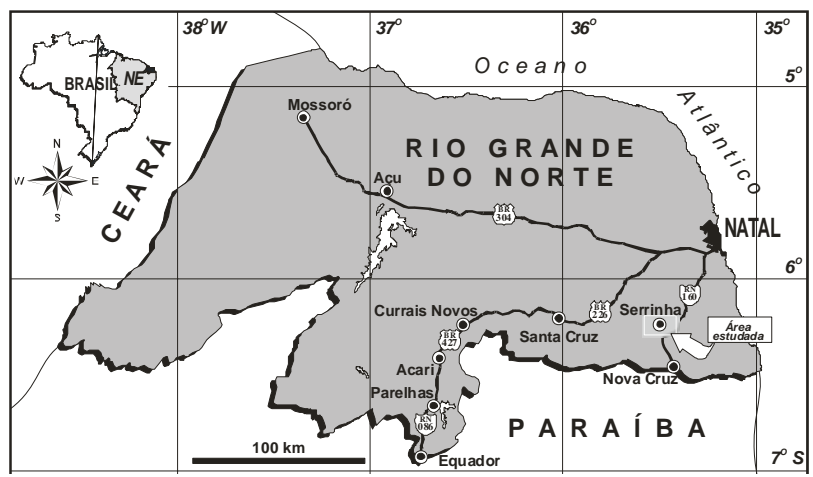

Figura 1 - Localização geográfica da área-piloto de Serrinha-RN. 


\section{Métodos Empregados}

Diversos métodos e técnicas de trabalho foram utilizados na caracterização da área. Todas as informações passaram por um rígido controle de qualidade, por um processamento adequado e foram interpretadas de forma integrada.

O mapeamento geológico enfocou a neotectônica e foi efetuado na escala de 1:50.000 objetivando discriminar litologias, trends estruturais dúcteis e frágeis e o seu atual comportamento aberto ou fechado, além de zonas de recarga. Foram utilizados ainda produtos de sensores remotos, como fotografias aéreas (1:70.000) e imagens de satélite Landsat 5 TM.

A geofísica aérea foi realizada em uma área com cerca de $100 \mathrm{~km}^{2}$ segundo linhas de vôo E-W com $13 \mathrm{~km}$ de extensão, eqüidistantes de $100 \mathrm{~m}$, além de linhas de controle N-S com $8 \mathrm{~km}$ de extensão, espaçadas por 500 $\mathrm{m}$. Foram utilizados três tipos de sensores rebocados em dois birds à velocidade de $144 \mathrm{~km} / \mathrm{h}$ (sistema towed bird, Fig. 2), a 30 e $45 \mathrm{~m}$ de altura do solo. O primeiro bird transporta os sensores eletromagnetométrico e magnetométrico, enquanto o segundo, o sistema Very Low Frequency (VLF). A taxa de amostragem temporal e espacial dos sensores é de 0,1 amostra/segundo e 1 amostra/4m. O sistema eletromagnetométrico fez uso de bobinas espaçadas por $6,4 \mathrm{~m}$ e com freqüências de 900 e $4500 \mathrm{~Hz}$ no arranjo coaxial e 900, 4500 e $33000 \mathrm{~Hz}$ no coplanar. Um dos objetivos do sensor magnetométrico é auxiliar no mapeamento geológico-estrutural, enquanto que o eletromagnetométrico é importante para caracterizar a área hidrogeologicamente, definindo as principais anomalias de condutividade. Em particular, os dados de elevação GPS corrigidos diferencialmente e subtraídos dos valores registrados pelo radar altímetro foram utilizados para compor o Modelo Digital do Terreno (MDT). O MDT representa um preciso mapa topográfico, sendo bastante útil para analisar feições geomorfológicas e estruturais.

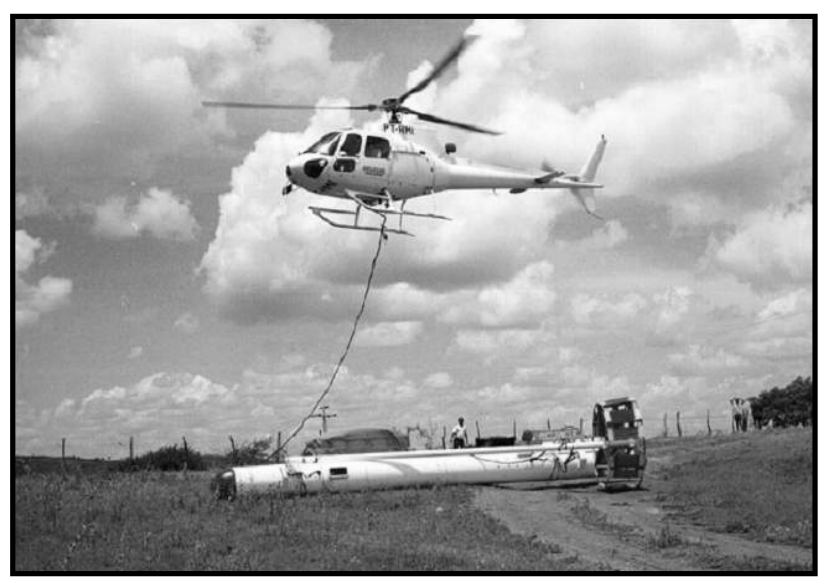

Figura 2 - Aeronave utilizada no método geofísico aeroportado destacando o "bird" que comporta os sistemas eletromagnetométrico e magnetométrico.
A geofísica terrestre foi executada para averiguar anomalias de condutividade identificadas pela aerogeofísica em locais específicos capazes de auxiliar o entendimento dos modelos de acumulação de água subterrânea. Empregou-se o método da eletroresistividade, arranjo Schlumberger, com aberturas de eletrodos de $2,5,10,20,50$ e $100 \mathrm{~m}$, espaçadas por 20 $\mathrm{m}$.

\section{Resultados}

O mapeamento geológico permitiu discernir diversas unidades litológicas, variando de gnaisses e rochas graníticas intrusivas a coberturas sedimentares (Fig. 3, Lima 2002). Afetando os litotipos cristalinos, ocorreram três episódios deformacionais dúcteis, sendo o último responsável pela atual configuração em macro-escala da área, exemplificada por dobras e zonas de cisalhamento. As estruturas frágeis também ocorrem segundo distintos episódios, sendo último considerado como o mais importante do ponto de vista hidrogeológico por controlar a atual tendência de comportamento aberto (direção EW) ou fechado (direção N-S) das descontinuidades. Esta distribuição de tensões local é correlata ao campo de tensões neotectônico regional e caracteriza-se, no plano horizontal, por compressão E-W e distensão N-S.

O mapa do campo magnético residual reduzido do IGRF (International Geomagnetic Reference Field), ilustrado na Figura 4, evidencia os principais trends estruturais dúcteis da área, por vezes correlatos a zonas de cisalhamento e, em outras, a contatos geológicos. Estas zonas de cisalhamento explicam as elevadas amplitudes magnéticas observadas, provavelmente geradas pela maior mobilização e concentração de minerais magnéticos ao longo de suas descontinuidades.

A partir do mapa de condutividade aparente para a freqüência de $4500 \mathrm{~Hz}$, arranjo vertical coaxial, com filtro passa-alta de $2 \mathrm{~km}$ (Fig. 5), pode-se visualizar diversas anomalias de condutividade hidrogeologicamente importantes. De uma forma geral, dominam na área anomalias de condutividade NW e NE. Geralmente as NW são correlacionáveis a fraturas com algum grau de saturação em água, ou alternativamente, preenchidas por material argiloso saturado. As anomalias NE, paralelas ao trend dúctil, normalmente refletem um maior grau de intemperização ao longo da foliação. Outras anomalias de condutividade refletem aumento na espessura de sedimentos em calhas de drenagens, a exemplo da porção SE da área. Por outro lado, em toda a região $\mathrm{N} \mathrm{e}$ NE da área, a região anomalamente condutiva indica a presença de expressivas coberturas sedimentares, conforme atestado pelo mapa geológico (vide Fig. 3).

O padrão topográfico da área, evidenciado através do MDT condiz com uma rede de drenagem estruturalmente controlada. As variações planialtimétricas visualizadas, integradas com as informações geológicas dos trends dúcteis e frágeis, e compostas com os dados de condutividade aparente da Figura 5, denotam os pontos nos quais a drenagem flui ao longo da foliação ou das fraturas (Fig. 4). 


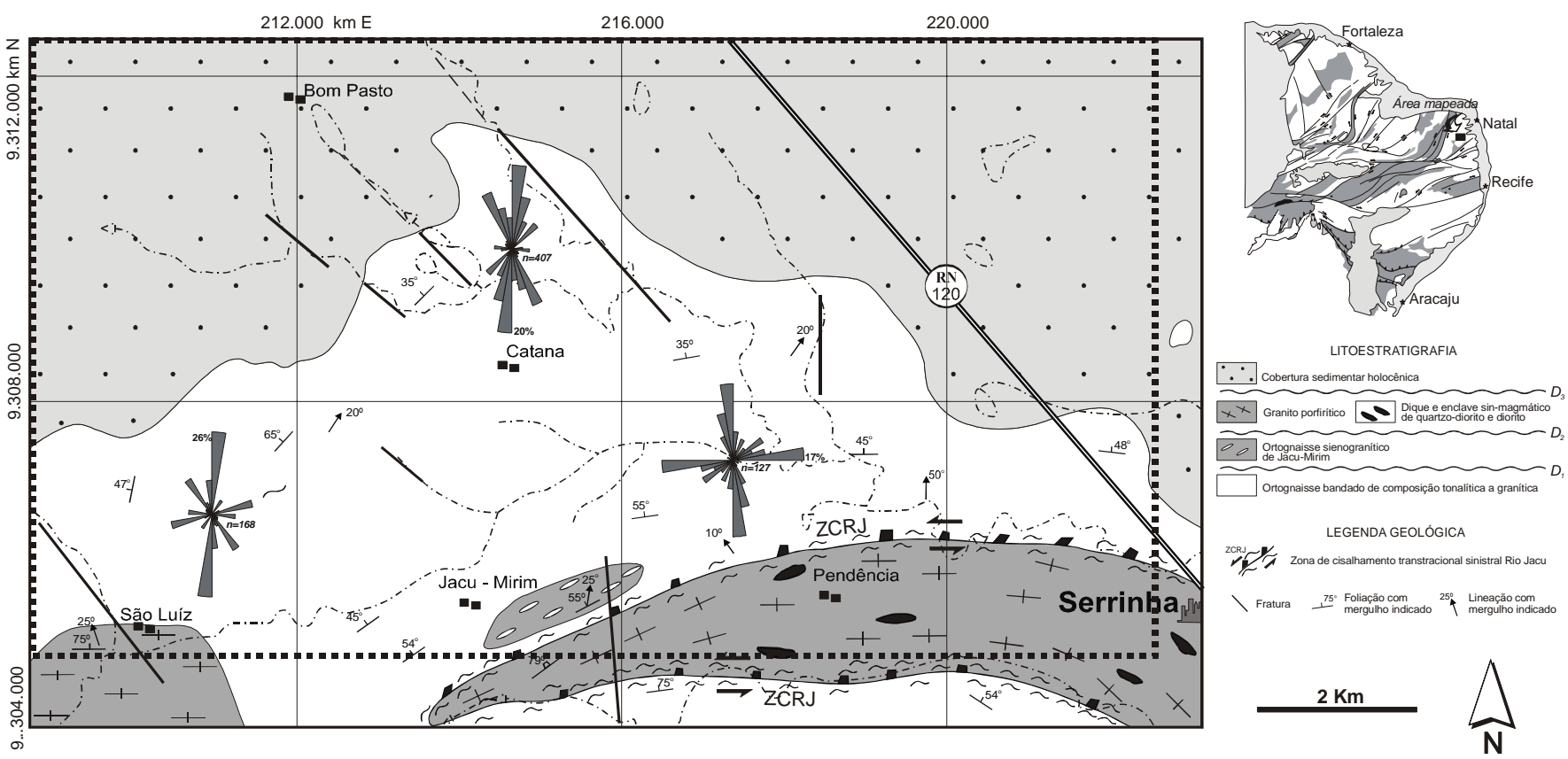

Figura 3 - Mapa geológico-estrutural da região de Serrinha-RN (Lima, 2002). O quadro pontilhado reflete a área de aquisição da geofísica aeroportada e as rosetas, as distribuições anqulares das fraturas em campo.

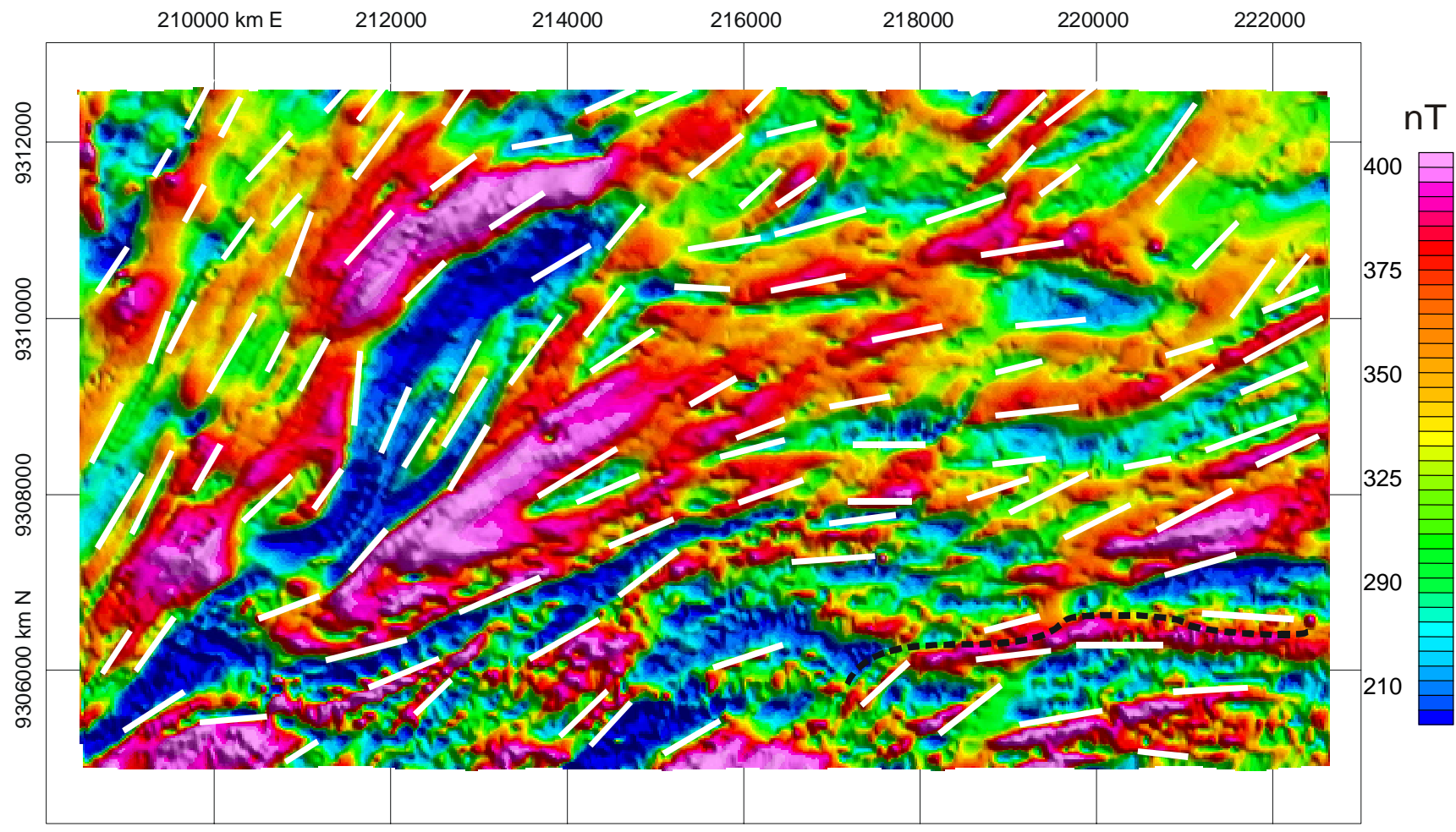

Figura 4 - Mapa interpretado do campo magnético residual com aplicação de filtro high-pass de 5 km. Neste caso são ressaltados os trends dúcteis observados em campo (em branco). A linha pontilhada em preto define um dos ramos de uma expressiva zona de cisalhamento. 


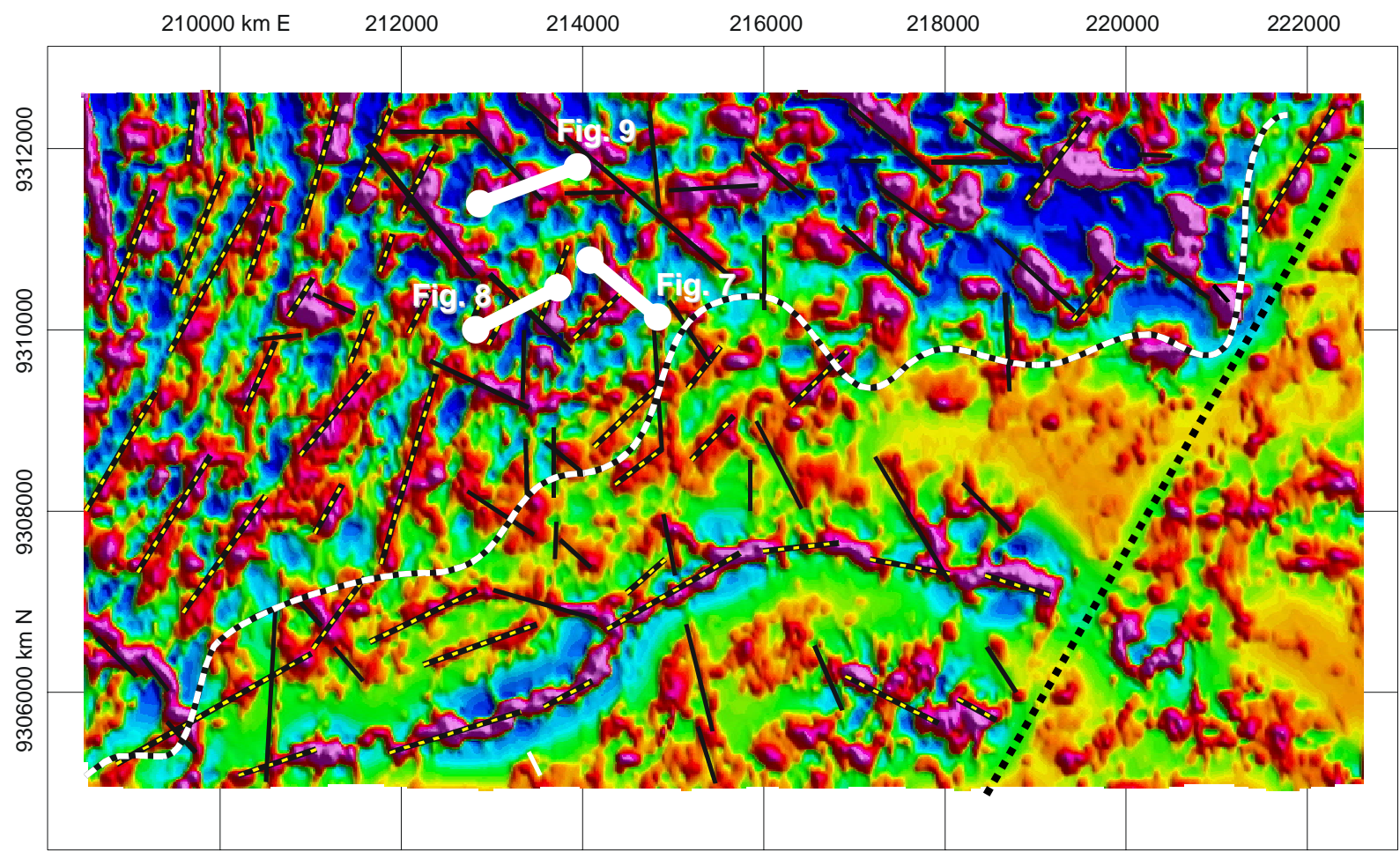

$\mathrm{mS} / \mathrm{m}$

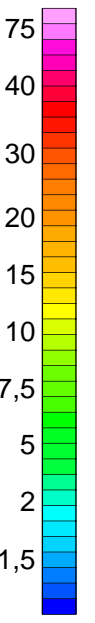

Figura 5 - Mapa residual pseudo-iluminado de condutividade aparente, filtro passa-alta de $2 \mathrm{~km}$, freqüência de 4.500 $\mathrm{Hz}$, arranjo vertical coaxial. As principais feições incluem fraturas (em preto contínuo), foliação (amarelo tracejado com contorno preto) e limite sul da zona de cobertura (preto pontilhado com contorno branco). Em preto pontilhado na porção leste do mapa, com direção NE, a localização de uma linha de tensão. Traços em branco definem a posição espacial de seções geoelétricas (Figs. 7, 8 e 9). Declinação da fonte de iluminação $45^{\circ}$ e inclinação $45^{\circ}$.

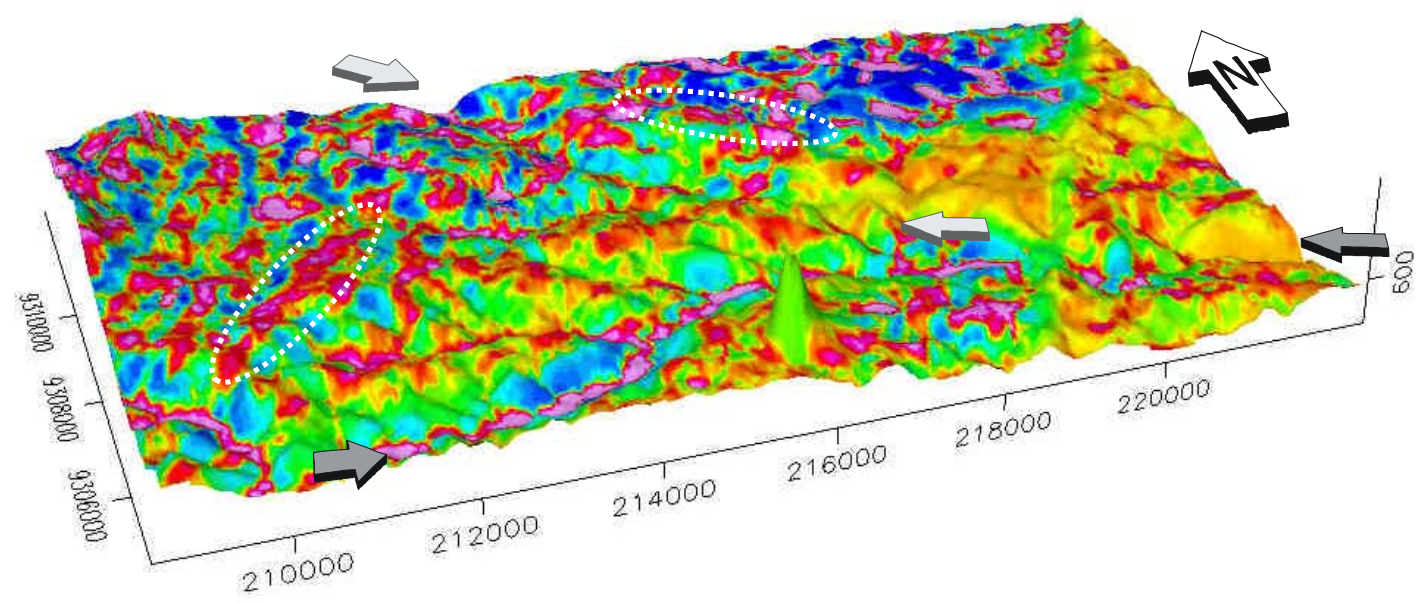

Figura 6 - Composição do mapa residual da condutividade aparente (freqüência de $4.500 \mathrm{~Hz}$, arranjo vertical coaxial e filtro passa-alta de $2 \mathrm{~km}$, Fig. 5) com o MDT (forma de relevo). As setas em cinza-claro marcam uma estrutura NW associada a uma anomalia de condutividade e topografia rebaixada; as setas em cinza-escuro marcam a anomalia de condutividade ao longo de uma zona de cisalhamento; as elipses em branco marcam anomalias de condutividade em altos topográficos subparalelas ao trend frágil NW (elipse na porção N) e ao trend dúctil NE (elipse na porção W). Exagero vertical de 20x, declinação da fonte de iluminação $45^{\circ}$ e inclinação $45^{\circ}$. 
Em função da grande distância existente entre a estação transmissora de ondas VLF e o local do levantamento, o sinal de VLF foi bastante degradado e o nível do sinal registrado não pôde ser discernido do nível de ruído local. Por este motivo, estes dados não serão discutidos.

Com relação à seção geoelétrica executada transversalmente a uma anomalia de condutividade NE (Fig. 7) é possível observar dois domínios geoelétricos contrastantes. Em sua porção SE, os valores mais elevados de resistividade aparente indicam o substrato cristalino subaflorante; na porção NW, o setor relativamente mais condutivo, com linhas de isocondutividade aparente horizontalizadas (subparalelas à foliação local), que se propagam desde a superfície até níveis mais profundos, é compatível com a presença de sedimentos. A potencialidade desta estrutura tipo calha elúvio-aluvionar é atestada por poço no local. Na seção ortogonal à anomalia NW (Fig. 8) observam-se feições condutivas, nas imediações das estações -20 m e 60 m, que não se propagam até pequenas aberturas de $A B / 2$. Elas refletem, portanto, a presença de fraturas em profundidade e que controlam a drenagem, conforme explícito no modelo riacho-fenda. Já na seção geoelétrica executada na porção NW da área estudada (Fig. 9) observam-se, em ambas as bordas (estações 20 a -120 $\mathrm{m})$, zonas anômalas em um padrão subverticalizado e que atingem aberturas de eletrodos $A B / 2$ da ordem de 50 $\mathrm{m}$ correlatas a zonas de fraturas. Observa-se ainda uma anomalia condutiva subhorizontalizada, localizada entre as estações 60 e $140 \mathrm{~m}$, para aberturas de $A B / 2$ superiores a $50 \mathrm{~m}$, a qual se interconecta às anomalias mais rasas. A anomalia condutiva mais profunda pode ser tentativamente explicada como o produto do intemperismo acentuado de zonas de fraturas subhorizontalizadas, ou do próprio bandamento, originando uma espécie de "bolsão de intemperismo", conforme modelo sugerido por Jardim de Sá et al. (2003).

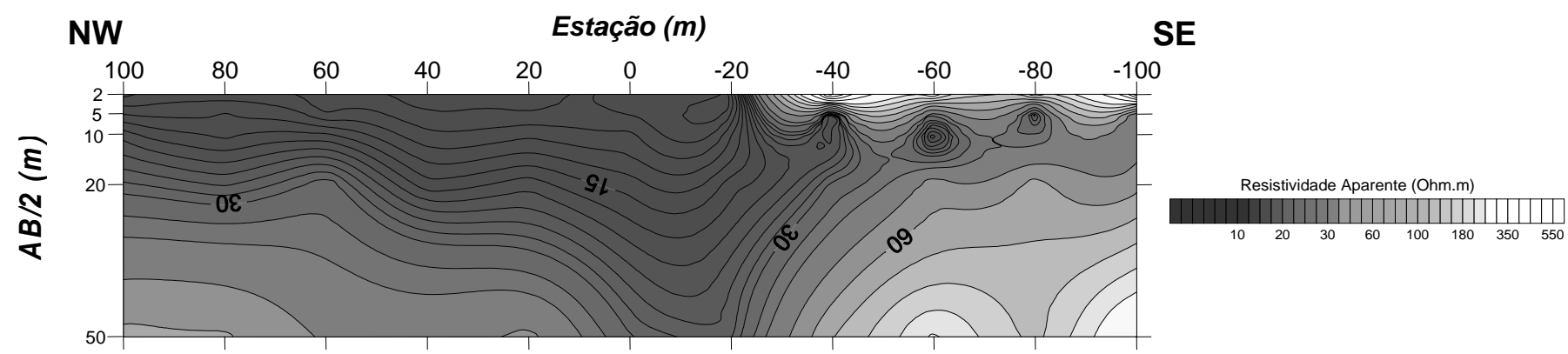

Figura 7 - Seção geoelétrica ortogonal a anomalia de condutividade NE (vide localização na Fig. 5), marcada em campo por drenagem (estação $0 \mathrm{~m}$ ) controlada por foliação. Observam-se linhas de isoresistividade aparente horizontalizadas a NW da estação $0 \mathrm{~m}$ imersas em uma zona condutiva e um padrão de linhas com gradiente mais elevado na porção SE, indicando domínio resistivo.

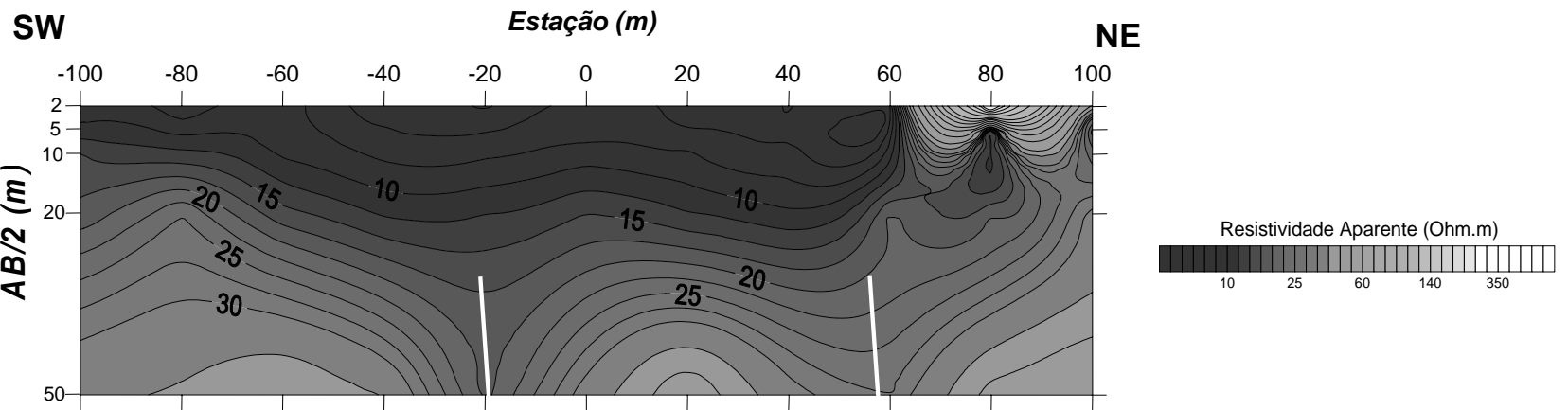

Figura 8 - Seção geoelétrica, ortogonal a anomalia de condutividade NW (vide localização na Fig. 5), marcada em campo por drenagem (estação $0 \mathrm{~m}$ ) controlada por fratura. Nas estações $-20 \mathrm{~m}$ e $60 \mathrm{~m}$ observam-se anomalias de condutividade verticalizadas que podem indicar zonas fraturadas em profundidade (traços em branco). Toda a região condutiva, observada para pequenas aberturas de eletrodos, está associada com material argilo-arenoso saturado em água, carreado pela drenagem. 


\section{SW}

Estação $(m)$

NE

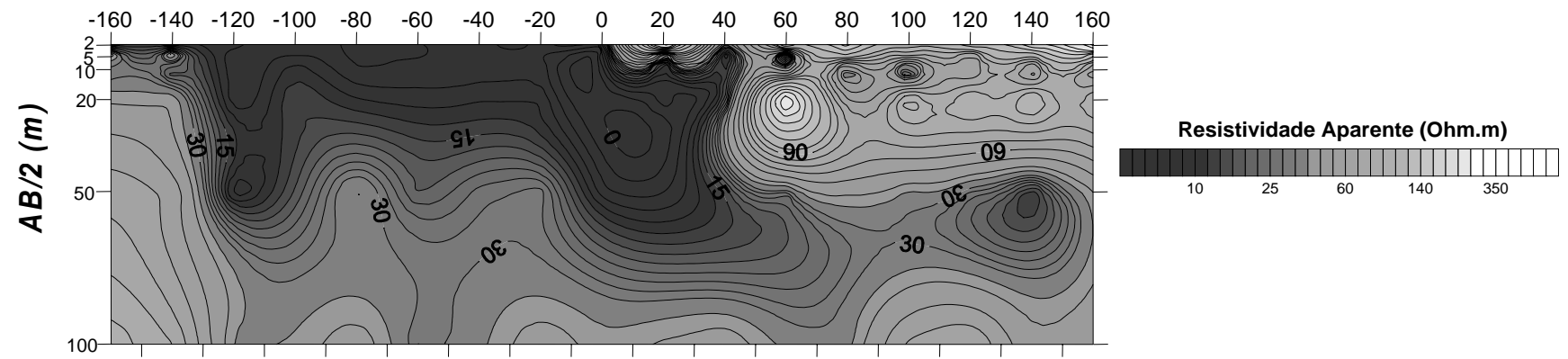

Figura 9 - Seção geoelétrica ortogonal a anomalia de condutividade NW (vide localização na Fig. 5), marcada em campo por lagoa e drenagem. As bordas da lagoa, delimitadas em superfície pelas estações 0 e $-100 \mathrm{~m}$, apresentam linhas de isoresistividade subverticalizadas. O mesmo ocorre na estação $-60 \mathrm{~m}$, para AB/2 superior a $50 \mathrm{~m}$. Pode-se ainda observar uma feição condutiva subhorizontalizada entre as estações 40 e $160 \mathrm{~m}$ (AB/2 de $50 \mathrm{~m}$ ), imersa em uma zona resistiva, a qual pode significar um acentuado grau de alteração das rochas ("bolsão de intemperismo"?).

\section{Discussão e Conclusões}

Constata-se que, geralmente, as estruturas hidrogeologicamente importantes no cristalino correspondem a estruturas planares, discretas quando analisadas isoladamente, mas que fazem parte de um complexo sistema interconectado de descontinuidades. A complexidade e heterogeneidade do embasamento dificultam a extrapolação em profundidade destas estruturas observadas em superfície. A geofísica, por sua vez, funciona como elo entre estas estruturas e a sua real morfologia em profundidade.

Os diferentes relacionamentos entre locais potenciais de acumulação de água subterrânea e o tipo de descontinuidade resultam nos diversos modelos de fluxo e armazenamento existentes. A coexistência entre as estruturas é fato e as descontinuidades representadas por anomalias condutivas que não ocorrem associadas a drenagens, por vezes presentes ao longo de altos topográficos (vide Fig. 6), não se enquadram nos modelos tradicionalmente utilizados nos trabalhos de locação e geralmente só podem ser detectadas através da geofísica.

Por vezes, os modelos de percolação e retenção de água subterrânea mostram-se adequados à realidade dos trabalhos de locação. Contudo, é necessário atentar para algumas de suas características. Do ponto de vista hidrogeológico, o delineamento das feições dúcteis e a sua correlação com as distribuições espacial e angular da rede de drenagem fornecem subsídios para delimitar trechos de ocorrência em potencial do modelo calha elúvio-aluvionar. Isto pode ser realizado pelo mapeamento de anomalias magnéticas e de condutividade. Por outro lado, onde houver a compatibilidade entre a rede de drenagem, anomalia condutiva e o trend frágil, mas incompatibilidade com anomalias magnéticas há potencial probabilidade de ocorrência do modelo tipo riacho-fenda.

Ressalta-se a probabilidade de sondagens executadas em calhas elúvio-aluvionares pouco evoluídas explicarem parte do insucesso das locações de poços no cristalino. Do ponto de vista de caracterização superficial, estas estruturas apresentam semelhanças ao tipo riacho-fenda. Isto é mais provável de ocorrer em regiões com capeamentos sedimentares expressivos que dificultam uma análise superficial mais detalhada. Nestes casos, o uso de métodos geofísicos é preponderante.

O modelo intitulado bolsão de intemperismo pode ser identificado a partir de técnicas geofísicas terrestres, delimitando a zona intensamente intemperizada. Neste caso, a estrutura é ocasionada por uma sucessão de efeitos intempéricos que afetam indiscriminadamente fraturas e foliação, gerando uma pseudo-porosidade intersticial, na qual a água subterrânea acumula-se. No entanto, o seu reflexo em superfície pode não ocorrer, dificultando desta forma a sua identificação.

\section{Agradecimentos}

Os autores agradecem à CAPES, ao projeto PADCT3FINEP-CNPq e a UFRN/PPGG pelo apoio financeiro e infra-estrutura, e ao projeto PROASNE por disponibilizar os dados aerogeofísicos utilizados.

\section{Referências}

Jardim de Sá, E.F.; Nascimento da Silva, C.C.; Coriolano, A.C.F.; Medeiros, W.E., 2003. Reavaliação da abordagem estrutural e modelos de ocorrência de água subterrânea em terrenos cristalinos. In: Hidrogeologia: conceitos e aplicações, CPRM (em impressão).

Lima, M.G., 2002. Mapeamento geológico-estrutural na região de Serrinha (RN), para apoio à interpretação de dados aerogeofísicos na pesquisa hidrogeológica. Relatório de Graduação, UFRN/CCET/DG, 81p.

Silva, J.A., 2000. Estruturas de acumulação de água subterrânea em rochas cristalinas: estudo geofísico e geológico de casos no Estado do Rio Grande do Norte. Diss. Mestrado, UFRN-CCET-PPGG, 92p.

Siqueira, L., 1963. Contribuição da geologia à pesquisa de água subterrânea no cristalino. SUDENE, Recife-PE. $51 p$. 
